\section{Reply: Relevance of Measurement Uncertainty for Quantitative Response Assessment of Breast Cancer Bone Metastases with ${ }^{18}$ F-Fluoride}

REPLY: We thank Laffon and Marthan for their interest in our study (1). They discuss the influence of measurement uncertainty on the ability to detect changes in measurements.

We refer them to previous work by members of our group (2) that compared ${ }^{18} \mathrm{~F}$-fluoride $\mathrm{K}_{\mathrm{i}}$ measurement derived from 60 -min dynamic PET acquisitions and a semipopulation input function approach, using the Hawkins model (3) and similar methods that allow $k_{4}$ to be fitted as a free variable, in 20 women who underwent scanning at 0,6 , and 12 mo after stopping bisphosphonate therapy. The paper reported similar precision errors (\% coefficient of variation) between all $\mathrm{K}_{\mathrm{i}}$ methods and $\mathrm{SUV}_{\text {mean }}(12.9 \%-14.8 \%$ and $10.1 \%$, respectively). That study also indicated that $\mathrm{K}_{\mathrm{i}}$ is likely to be a more reliable index of changes in bone turnover than SUV in studies in which the treatment alters the arterial input function.

In our current study, $\mathrm{K}_{\mathrm{i}}$ is calculated from a single static scan at 60 min after injection (1). This is, in effect, measuring SUV, with all the benefits of good precision, and then converting this into a $\mathrm{K}_{\mathrm{i}}$ measurement using plasma concentration data from venous blood samples taken more than 30 min after injection when venous and arterial blood are in equilibrium. The plasma measurements have excellent precision and accuracy as blood samples can be timed to a few seconds, the plasma samples are weighed to an accuracy of $1 \mathrm{mg}$, and the counting statistical errors in the $\gamma$-counter are about $1 \%$. Although we add a fixed residual curve, it is important to note that approximately $75 \%-80 \%$ of the total area under the curve at $60 \mathrm{~min}$ comes from the single exponential. Also, if the bone treatment alters the input function, then it is the terminal exponential that will show the greatest change, not the residual function, which reflects the bolus peak and the early rapid mixing with soft tissue.

We therefore believe that precision errors for our method of measuring $\mathrm{K}_{\mathrm{i}}$ and those for SUVs will be similar and that a $25 \%$ cutoff is a reasonable starting point to differentiate progressive disease from non-progressive disease for ${ }^{18} \mathrm{~F}$-fluoride $\mathrm{SUV}_{\max }$, $\mathrm{SUV}_{\text {mean }}$, and $\mathrm{K}_{\mathrm{i}}$. We also believe that for treatment monitoring, $\mathrm{K}_{\mathrm{i}}$ is a more reliable parameter to detect changes in bone turnover than SUVs, particularly when the therapy may affect the arterial input function.

\section{REFERENCES}

1. Azad G, Siddique MM, Taylor B, et al. Does measurement of ${ }^{18}$ F-fluoride metabolic flux improve response assessment of breast cancer bone metastases compared with standardized uptake values in ${ }^{18} \mathrm{~F}$-fluoride PET/CT? J Nucl Med. July 24, 2018 [Epub ahead of print].

2. Siddique M, Frost ML, Blake GM, et al. The precision and sensitivity of ${ }^{18} \mathrm{~F}-$ fluoride PET for measuring regional bone metabolism: a comparison of quantification methods. J Nucl Med. 2011;52:1748-1755.

3. Hawkins RA, Choi Y, Huang SC, et al. Evaluation of the skeletal kinetics of fluorine-18-fluoride ion with PET. J Nucl Med. 1992;33:633-642.

Gurdip Azad Muhammad Siddique Benjamin Taylor Adrian Green

\author{
Jim O'Doherty \\ Joanna Gariani \\ Glen Blake \\ Janine Mansi \\ Vicky Goh \\ Gary Cook* \\ *St Thomas' Hospital \\ London, SE1 7EH, United Kingdom \\ E-mail: gary.cook@kcl.ac.uk
}

Published online Mar. 8, 2019.

DOI: 10.2967/jnumed.119.226555

\section{Economic Sanctions Endanger Nuclear Medicine Services in Iran}

TO THE EDITOR: The recent withdrawal of the United States from the Iran nuclear deal, followed by economic, trade, and financial sanctions against Iran, has had a deleterious effect on nuclear medicine, on the supply of both radiotracers and spare parts for nuclear medicine devices. Although medicine is apparently not included in the list of sanctions, medical companies find it very difficult to be able to do any transactions because of secondary sanctions, aviation and transportation embargoes, as well as financial restrictions. Payment for the drugs or instruments and shipment of the goods to and from Iran have turned to a lengthy, difficult and risky task.

The multidisciplinary network of Iranian nuclear medicine scientists, with members all around the world, would like to inform the medical community about these negative consequences of the current economic sanctions of the United States on the healthcare of the Iranian population.

The Iranian nuclear medicine services are confronted throughout the country with major difficulties in purchasing radiopharmaceuticals for imaging and therapeutic purposes.

We are concerned that, in addition, the domestically produced radiopharmaceuticals, which depend on raw materials from abroad, will undergo a dramatic shortage. We strongly believe that any medical shortage including restricted supply of radiopharmaceuticals seriously endangers the health of patients and restricts the basic universal human rights for health.

The exact effects of the sanctions on Iranian people cannot be quantified, but some authors reported the harmful effects of previous economic sanctions on healthcare $(1,2)$. It should be emphasized that nuclear medicine is an indispensable part of the multidisciplinary care of patients, and the shortage of radiopharmaceuticals will have an increasing impact on the healthcare of the Iranian population.

We therefore request urgently the support of international and U.S. nuclear medicine associations and hope that they will join us in our plea to the U.S. administration to ascertain the supply of life-saving radiopharmaceuticals for Iranian patients. The network of Iranian nuclear medicine scientists urges the community to support protection of full nuclear medicine services in Iran.

\section{DISCLOSURE}

No potential conflict of interest relevant to this article was reported. 